$\S=$ 圆

\title{
Vibration and damping characteristics of sisal and glass fiber reinforced polyester composite
}

\author{
G. SathishKumar ${ }^{1}$, M. Chandrasekaran ${ }^{2}$, T. Vinod Kumar ${ }^{1}$, P. Vivek ${ }^{1}$ \\ ${ }^{1}$ Assistant Professor, Department of Mechanical Engineering, Vels Institute of Science, Technology \& Advanced Studies, Chennai \\ ${ }^{2}$ Professor and Director, Department of Mechanical Engineering, Vels Institute of Science, Technology \& Advanced Studies, Chennai \\ *Corresponding author E-mail: gsk032sathish@gmail.com
}

\begin{abstract}
This study aims to evaluate the result of experimental investigation carried out on free vibration characteristics and damping factors of short sisal \& glass fiber polyester composite. Composites specimen is fabricated in random fiber orientation using to hand lay-up method by Influence of fiber length $(10 \mathrm{~mm})$ and weight percentage $(5,10,15,20 \mathrm{wt}$. \%). Studies revealed that increase in the fiber content will in-crease the natural frequency $(\mathrm{Hz})$ and decrease the damping factor is given by the composites having a fiber loading of $20 \mathrm{wt}$. percentage ranges. The properties were compared with neat polyester. In this work, increasing fiber content increases the natural frequency (Hz) and decrease the damping factors of the composite.
\end{abstract}

Keywords: Natural and Synthetic Fiber (Sisal \& Glass); Polyester Resin; Free Vibration Testing (FVT)

\section{Introduction}

In many applications, natural fiber composites are realistic alternative to synthetic fiber composites, since the fibers possess many comparatively recognitions, such as low density, high specific strength, low cost and renewability. The most commonly used plant fibers for polymer reinforcement are sisal, jut, banana, flax, ramie, hemp, etc., which already contribute to various engineering applications. The recitals of amalgamated resources are generally based on their perfunctory distinctiveness, such as tensile, flexural, compression and impact properties table 1 .

These characteristics are crucial to ascertain the material performance in diversified circumstances. However, natural fiber reinforced composites are not fully investigated for structural engineering applications especially under dynamic loading conditions. Damping is one of the significant factors allied with the vibrant conduct of the materials because of its influence on systems feat, like safety and reliability [1], vibrations elevate high- noise levels, malfunctioning of stress exhaustion, premature wear and hazardous working conditions. Structures can experience too much of pulsation when the forceful loading creates vibrations at normal incidence of the material.

Synthetic composites are made from synthesized polymers or small molecules. Synthetic fibres do not depend either on an agricultural crop or animals farming. In addition, basically synthetic fibre composite properties are stronger than natural composite but synthetic fibres burn more readily than natural and cost of cost of making materials would be more. Some of the synthetic composites are carbon/graphite, boron, Kevlar and ceramic composite.

Fiberglass (or fiberglass) is a type of fiber reinforced plastic where the reinforcement fiber is specifically glass fiber. The glass fiber may be randomly arranged but is commonly woven into a mat. The plastic matrix may be a thermosetting plastic most often epoxy polyester resin or vinyl ester, or a thermoplastic. The glass fibers are made of various types of glass depending upon the fiberglass use.
These glasses all contain silica or silicate, with varying amounts of oxides of calcium, magnesium, and sometimes boron. To be used in fiberglass, glass fibers are made with very low levels of defects. Fiber glass is a strong lightweight material and is used for many products. Although it is not as strong and stiff as composites based on carbon fiber, it is less brittle, and its raw materials are much cheaper. Its bulk strength and weight are also better than many metals, and it can be more readily molded into complex shapes. Applications of fiberglass include aircraft, boats, automobiles, bath tubs and enclosures, swimming pools, etc.

Table 1:.Physical and Mechanical Properties of Sisal/Glass Fibers

\begin{tabular}{lll}
\hline Properties & Sisal & Glass \\
\hline Density $\left(\mathrm{g} / \mathrm{cm}^{3}\right)$ & $1.33-1.45$ & 2.55 \\
Tensile strength & $510-700$ & 2400 \\
Young's modulus(GPa) & $9-38$ & $70-90$ \\
Moisture Absorption \% & 11 & 3 \\
Elongation at break $(\%)$ & $2.2-2.9$ & - \\
\hline
\end{tabular}

Hence, consideration of the whole vibration effect on the materials is very important for the effectual design and use of this composite. Free vibration test and Damping factors are important techniques to study the mechanical behavior of polymer composite resources. Prevalent revisions have been made on the method of vibration damping in polymers [2-6]. However, damping mechanisms in FRP materials vary completely from conventional polymers [11-14]. In case of composite materials, the occurrence of fillers or strengthening agents formulate multipart interior structures in the material in which the damping behaviors rely not only on properties of individual materials but also on many other features, e.g. volume fraction of fillers table 2 , the quality of the interface, loading direction and plasticization of polymer[4-7]. There are various energy indulgence mechanisms in fiber-reinforced composites such as visco-elastic nature of matrix and/or fiber materials, frictions caused by the slip 
in the matrix/fiber edges, energy indulgence at clefts and delaminating caused at dented spots, visco-plastic and thermo elastic damping [1].

The hand lay-up method time of curing depends on type of polymer used for composite processing. For example, for epoxy based system, normal curing time at room temperature is $24-48$ hours. This method is mainly suitable for thermosetting polymer based composites. Capital and infrastructural requirement is less as compared to other methods. Production rate is less and high volume fraction of reinforcement is difficult to achieve in the processed composites. Hand lay-up method finds application in many areas like aircraft components, automotive parts, boat hulls, deck etc. Generally, the materials used to develop composites through hand lay-up method also volume and mass calculation is given in table 2 .

Table 2:. Volumes and Mass Calculation of Sisal and Glass Fiber

\begin{tabular}{lllll}
\hline \multirow{2}{*}{ Sample } & $\begin{array}{l}\text { Sisal } \\
\text { Volume }\left(\mathrm{cm}^{3}\right)\end{array}$ & Mass $(\mathrm{g})$ & $\begin{array}{l}\text { Glass } \\
\text { Volume }\left(\mathrm{cm}^{3}\right)\end{array}$ & Mass $(\mathrm{g})$ \\
\hline Sample 1 & 13.5 & 17.95 & 71.25 & 34.45 \\
Sample 2 & 27 & 35.91 & 67.50 & 68.85 \\
Sample 3 & 40.5 & 53.86 & 63.75 & 103.27 \\
Sample 4 & 54 & 71.82 & 60.00 & 137.7 \\
\hline
\end{tabular}

\section{Materials and method}

Sisal and glass fiber and unsaturated polyester resin are used as reinforcement and matrix. The composites were fabricated with sisal and glass fiber cut to a length of $10 \mathrm{~mm}$ were evenly arranged in a mold measuring $300 \mathrm{~mm} \times 300 \mathrm{~mm} \times 3 \mathrm{~mm}$ for preparing the samples. Various mass percentage $(0,5,10,15$ and 20$)$ of sisal and glass fiber were used the preparation of samples. To perform dynamic test, specimens were held as a cantilever beam. The free end of each sample was attached to the accelerometer, and vibration was triggered using a rubber hammer. Four specimens with the size of $220 \mathrm{~mm} \times 30 \mathrm{~mm} \times 3 \mathrm{~mm}$ were used for vibration test and the average value is reported. The vibration acceleration time history was recorded by the data acquisition program. The logarithmic decrement is used for calculating the damping ratio $(\xi)$ of the cantilever beam from recorded acceleration time histories based on the following equation 1.

$$
\xi=1 / 2 \pi j \ln (x i / x i+j)
$$

Where $x i$ is the peak acceleration of the ith peak and $x i+j$ is the peak acceleration of the peak $j$ cycles after ith peak

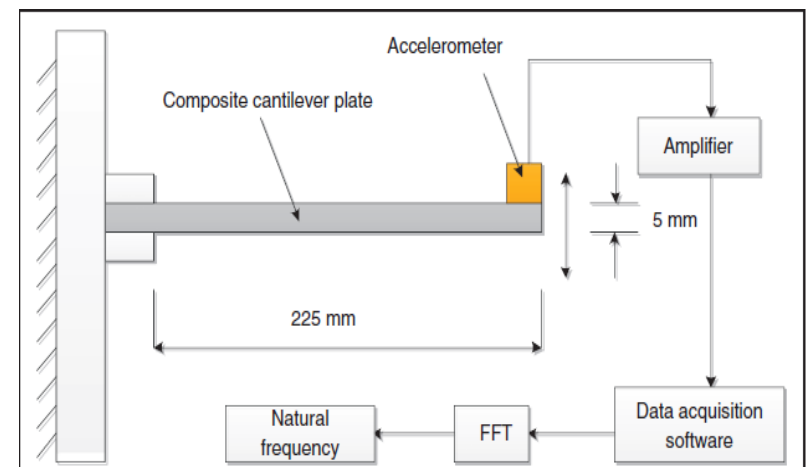

Fig. 1: Schematic View of Vibration Test System.

\section{Result and discussion}

Free vibration testing (FVT)

Free vibration and time histories of pure polyester and $5 \mathrm{wt} \%$, $10 \mathrm{wt} \%, 15 \mathrm{wt} \%, 20 \mathrm{wt} \%$ sisal fiber-reinforced polyester composite was carried out.

The average damping ratios and natural frequencies of the composites, calculated according to section. Shown fig.2 (a), (b), (c), (d), (e) carried out the natural frequency of the polyester resin,
Frequency Vs Amplitude of pure polyester and 5wt $\%, 10 \mathrm{wt} \%$, $15 \mathrm{wt} \%, 20 \mathrm{wt} \%$ with respect to time.

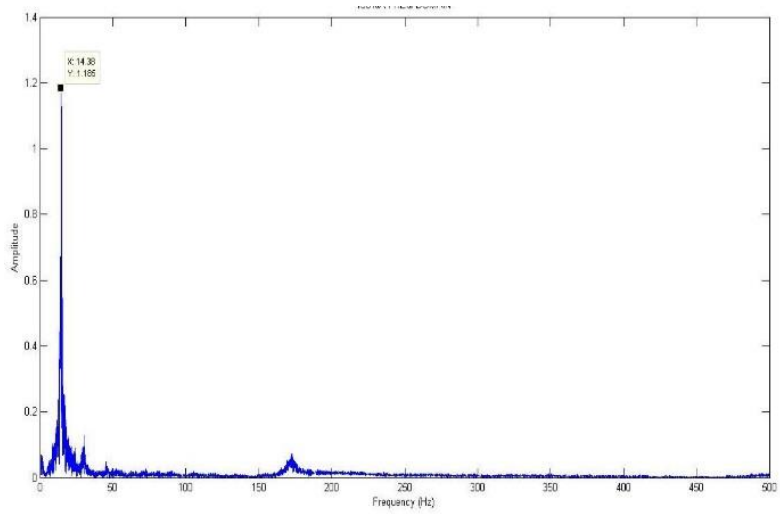

Fig. 2: (A) Sample1, Freq (Hz) vs Amp (G).

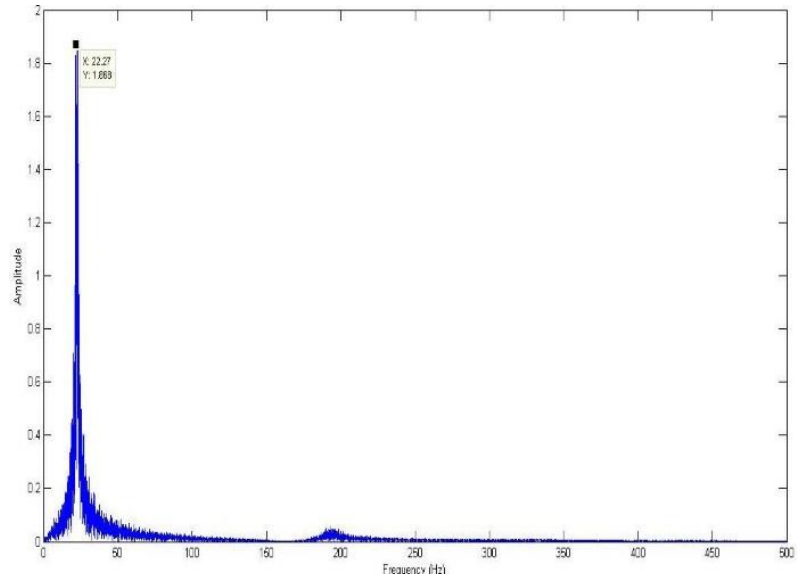

Fig. 2: (B) Sample2, Freq (Hz) vs Amp (G)

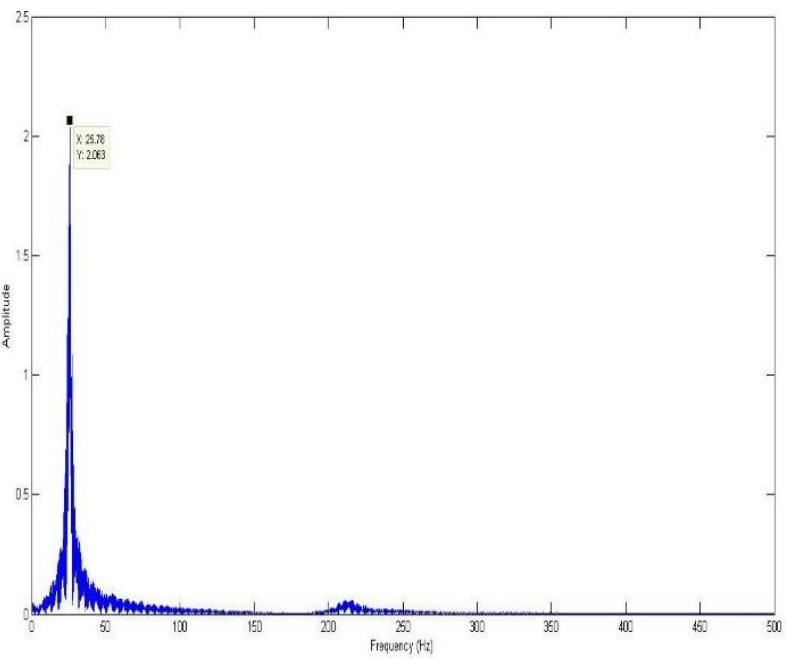

Fig. 2: (C) Sample3, Freq (Hz) vs. Amp (G). 


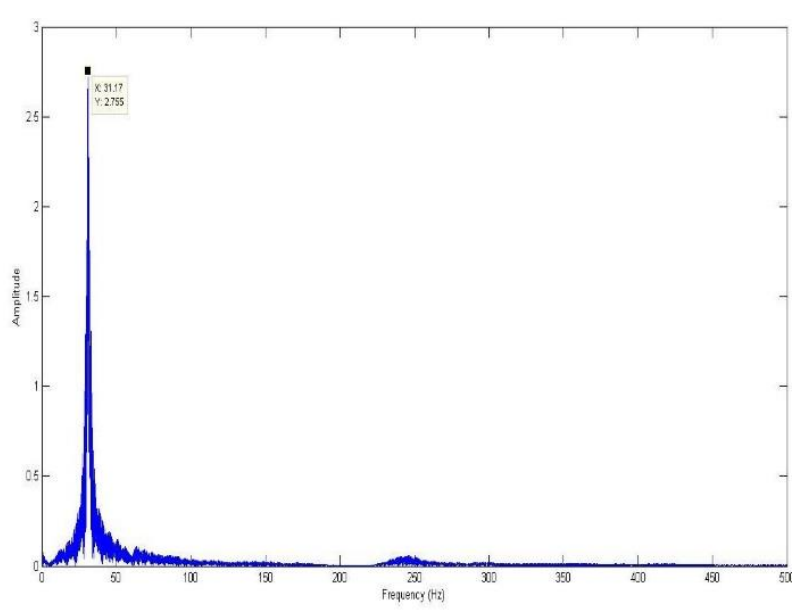

Fig. 2: (d) Sample4, Freq (Hz) vs. Amp (g)

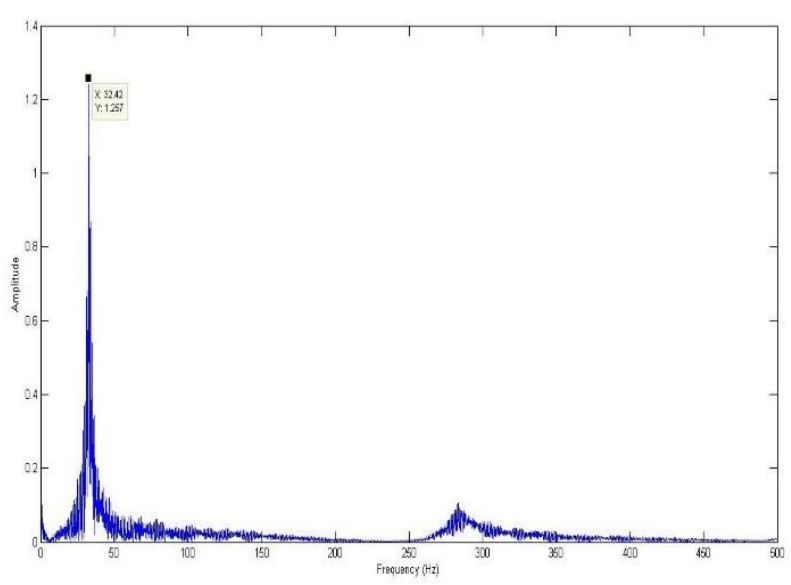

Fig. 2: (E) Sample5, Freq (Hz) vs. Amp (G).

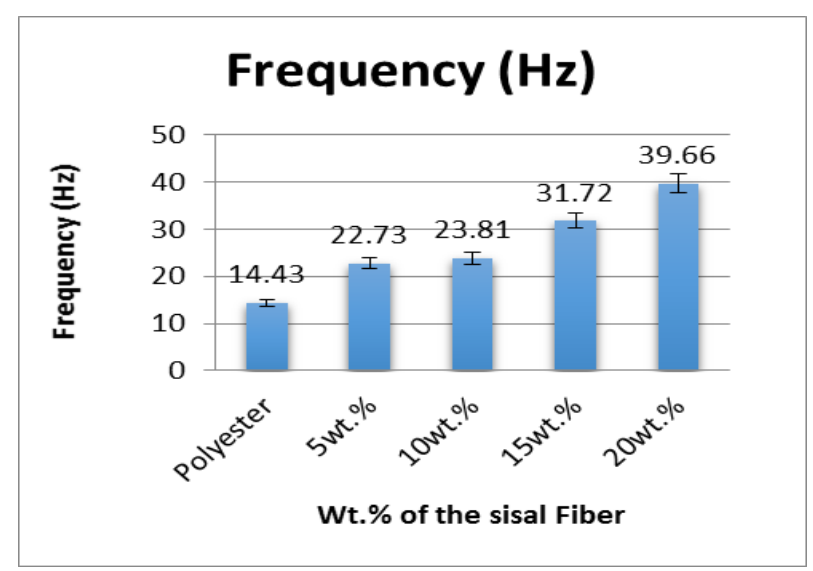

Fig. 3: Natural Frequency.

Table 3: Natural Frequency

\begin{tabular}{|c|c|c|c|c|c|}
\hline Samples & polyester & 5wt.\% & $10 \mathrm{wt} . \%$ & $15 \mathrm{wt} . \%$ & $20 \mathrm{wt} . \%$ \\
\hline 1 & 14.38 & 22.27 & 22.85 & 31.17 & 32.42 \\
\hline 2 & 14.3 & 23.13 & 25.78 & 31.88 & 43.75 \\
\hline 3 & 14.61 & 22.81 & 22.81 & 32.11 & 42.81 \\
\hline Average & 14.43 & 22.73 & 23.81 & 31.72 & 39.66 \\
\hline
\end{tabular}

Fig.3. Natural Frequency values of various composite materials are shown. The value of Natural Frequency of pure polyester resin is $14.43 \mathrm{~Hz}$ and polyester resin with $5 \mathrm{wt} . \%, 10 \mathrm{wt} . \%, 15 \mathrm{wt} . \%$ and 20wt. $\%$ of the sisal fiber values are $22.73 \mathrm{~Hz}, 23.81 \mathrm{~Hz}, 31.72 \mathrm{~Hz}$ and $39.66 \mathrm{~Hz}$ respectively. It is found that the maximum value of Natural Frequency of $39.66 \mathrm{~Hz}$ is obtained with the addition of 20wt. \% sisal fiber to the composite material.

Damping Curve

Free vibration test for pure polyester and $5 \mathrm{wt} \%, 10 \mathrm{wt} \%, 15 \mathrm{wt} \%$, $20 \mathrm{wt} \%$ sisal fiber-reinforced polyester composite was carried out and the obtained results are plotted as graph which gives the damping ratio of the composite sample.

Fig.4. (a) represents the Time Vs Acceleration graph for pure polyester. Similarly Fig.4. (b), (c), (d), and (e) represents the Time Vs Acceleration graph for sample $\%, 10 \mathrm{wt} \%, 15 \mathrm{wt} \%, 20 \mathrm{wt} \%$ sisal fiber-reinforced polyester composite respectively.

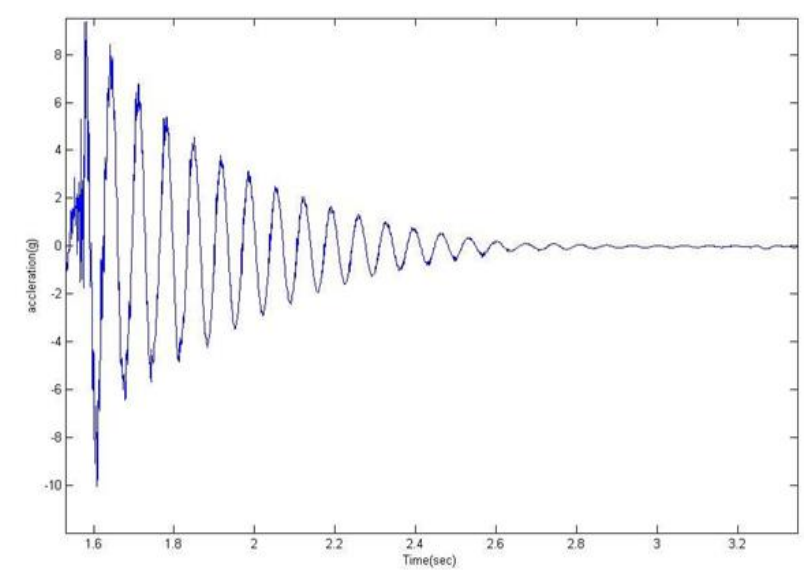

Fig. 4: (A) Time History of Pure Polyester.

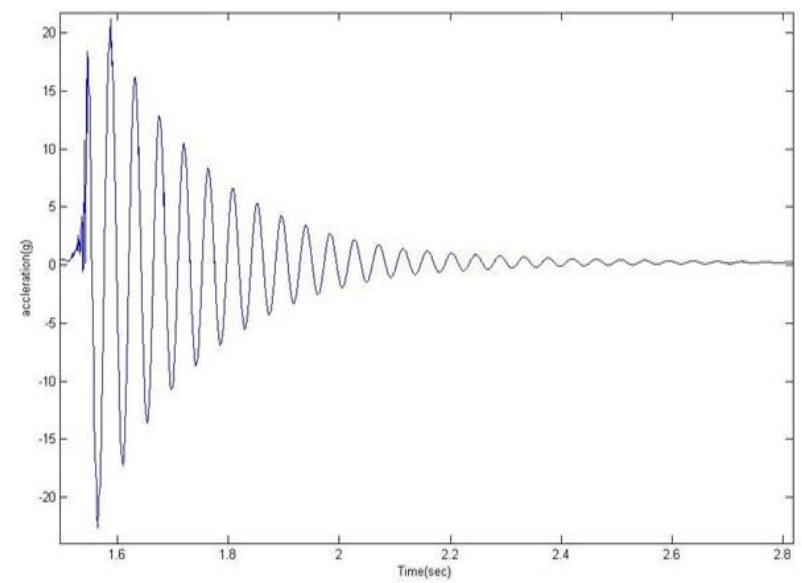

Fig. 4: (B) Time History of 5 wt. Percentage of Sisal Fiber.

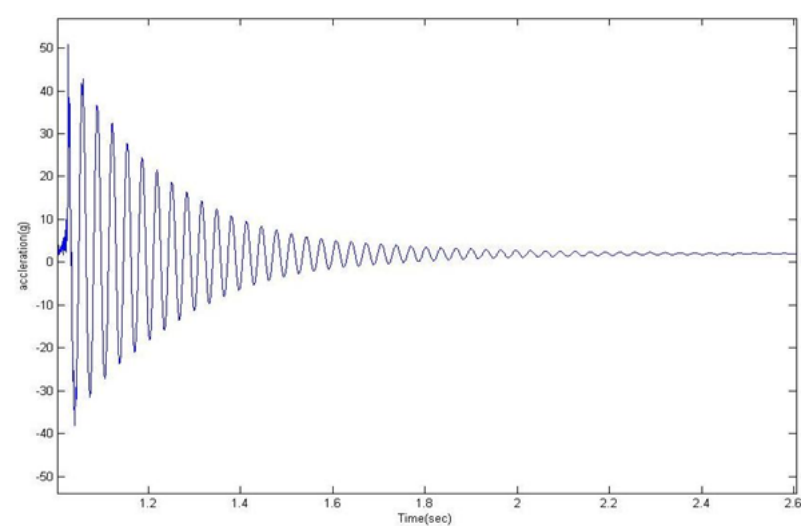

Fig. 4: (C) Time History of 10wt. Percentage of Sisal Fiber. 


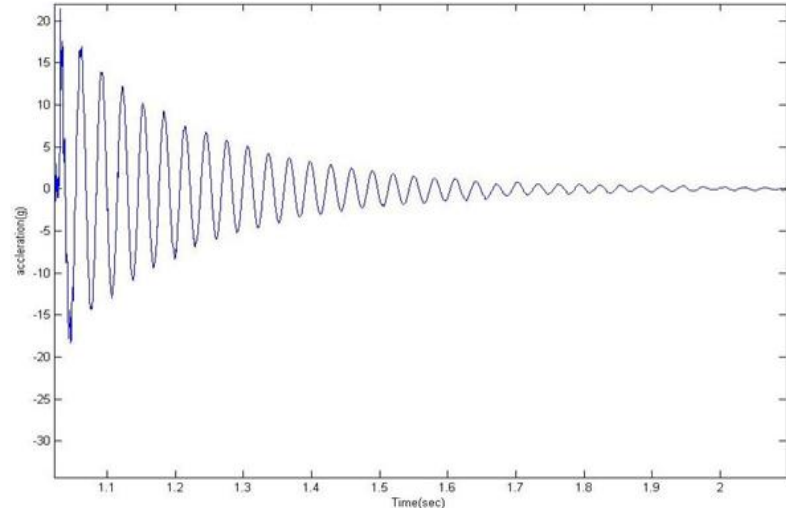

Fig. 4: (D) Time History of 15wt. Percentage of Sisal Fiber.

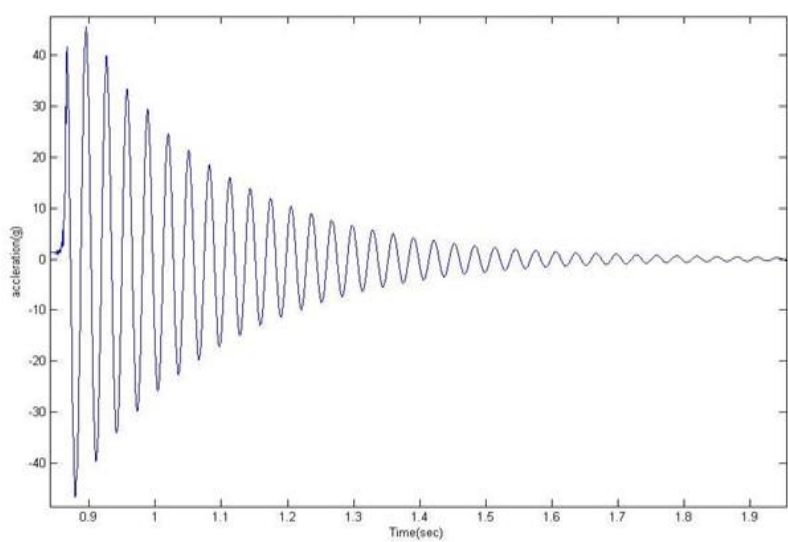

Fig. 4: (E) Time History of 20wt. Percentage of Sisal Fiber.

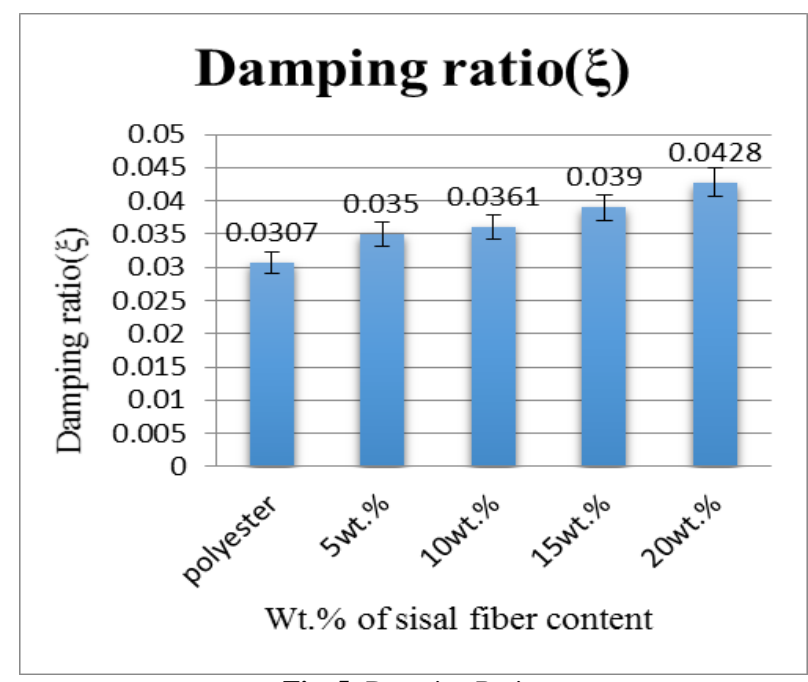

Fig. 5: Damping Ratio.

Calculation For Damping Ratio

Find out the Damping ratio of the material using logarithmic decrement

Formula-2

$\ln \frac{\mathrm{x}_{0}}{\mathrm{x}_{1}}=\frac{2 \pi z}{\sqrt{1-\mathrm{z}^{2}}}$

Where:

$\mathrm{X}_{0}$ is $\mathrm{i}^{\text {th }}$ peak

$\mathrm{X}_{1}$ is the peak acceleration of the peak after $\mathrm{i}^{\text {th }}$ peak.

Pure Polyester

$x_{0}=4.799$

$x_{1}=3.792$ $x_{2}=3.323$

$x_{a}=2.697$

These values are taken from the acceleration Vs time graph of pure polyester.

$\ln \frac{4.799}{3.792}=\frac{2 \pi \varepsilon}{\sqrt{1-\varepsilon^{2}}}$

$\varepsilon=0.0307$

Table 4: Damping Ratios

\begin{tabular}{llllll}
\hline Samples & Polyester & $\begin{array}{l}5 \mathrm{wt} \% \\
\text { of Fi- } \\
\text { ber }\end{array}$ & $\begin{array}{l}10 \mathrm{wt} \% \\
\text { of Fiber }\end{array}$ & $\begin{array}{l}15 \mathrm{wt} \% \\
\text { of Fiber }\end{array}$ & $\begin{array}{l}20 \mathrm{wt} \% \\
\text { of Fiber }\end{array}$ \\
\hline 1 & 0.0375 & 0.0321 & 0.0367 & 0.0693 & 0.0346 \\
2 & 0.0264 & 0.0366 & 0.0358 & 0.0232 & 0.0384 \\
3 & 0.0283 & 0.0369 & 0.0358 & 0.0247 & 0.0555 \\
Average & 0.0307 & 0.0352 & 0.0361 & 0.0392 & 0.0428 \\
\hline
\end{tabular}

Fig.5.The Damping Ratio values of various composite materials are shown. The value of Damping Ratio of polyester resin is 0.0307 and polyester resin with $5 \mathrm{wt} . \%, 10 \mathrm{wt} . \%, 15 \mathrm{wt} . \%$ and $20 \mathrm{wt} . \%$ of the sisal fiber values are $0.035,0.0361,0.039$ and 0.0428 respectively. It is found that the maximum value of damping ratio of 0.0428 is obtained with the addition of $20 \mathrm{wt}$. \% sisal fiber to the composite material.

\begin{tabular}{lll}
\multicolumn{3}{c}{ Table 5: Decay Time } \\
\hline S.no & Sample & Time(sec) \\
\hline 1 & Pure polyester & 3 \\
2 & 5wt.5 of fiber & 2.6 \\
3 & 10wt.5 of fiber & 2.4 \\
4 & 15wt.5 of fiber & 2.1 \\
5 & 20wt.5 of fiber & 1.9 \\
\hline
\end{tabular}

It is observed that the decay time decreases with the addition of sisal fiber, the minimum decay time is in $20 \mathrm{wt}$. \% of sisal fiber composite materials.

Free vibration testing (FVT)

Free vibration and time histories of pure polyester and $5 \mathrm{wt} \%$, $10 \mathrm{wt} \%, 15 \mathrm{wt} \%, 20 \mathrm{wt} \%$ glass fiber-reinforced polyester composite was carried out.

The average damping ratios and natural frequencies of the composites, calculated according to section. Shown fig.6. (a), (b), (c), (d), (e) carried out the natural frequency of the polyester resin, Frequency Vs Amplitude.

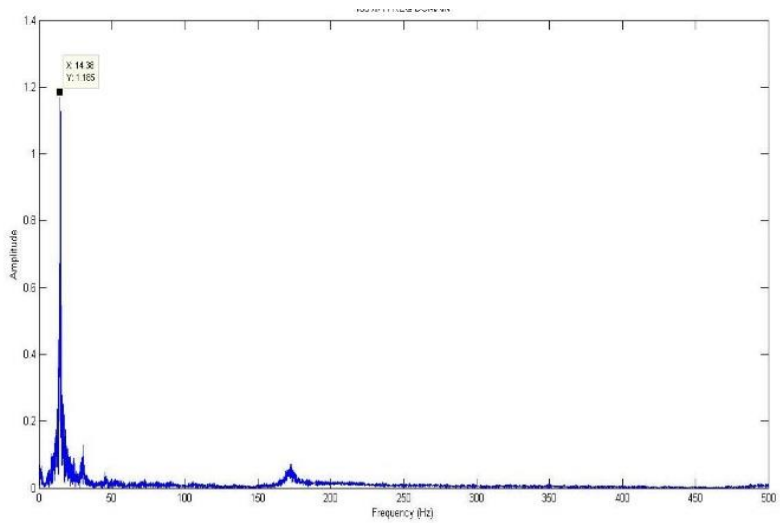

Fig. 6: (A) Sample1, Freq (Hz) vs Amp (G). 


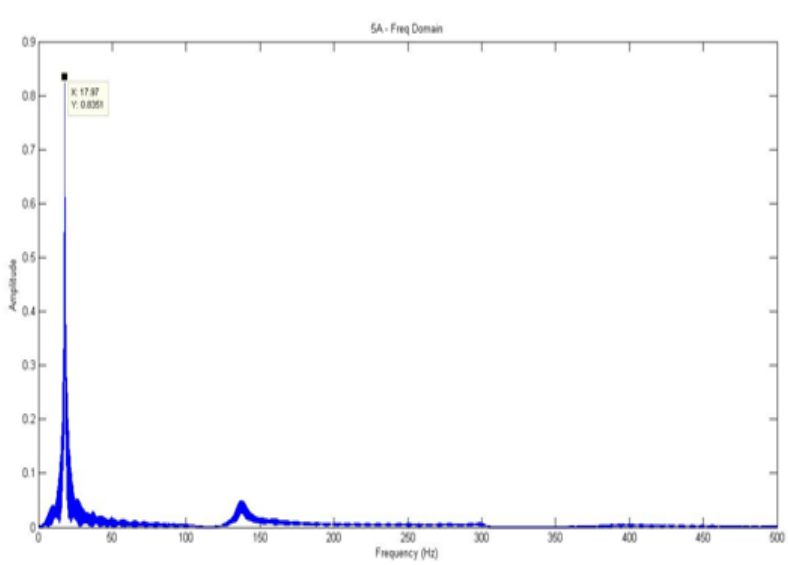

Fig. 6: (B) Sample2, Freq (Hz) vs Amp (G).

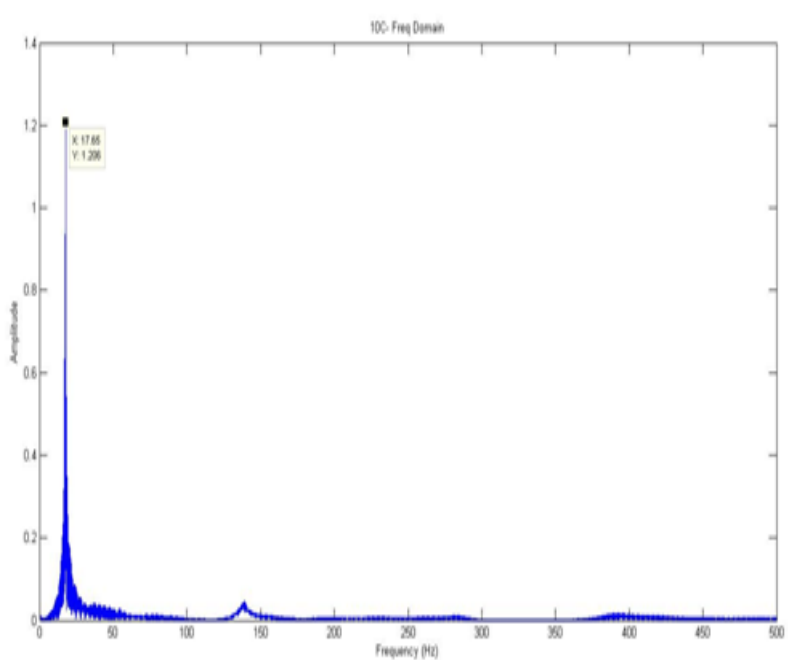

Fig. 6: (C) Sample3, Freq (Hz) vs Amp (G).

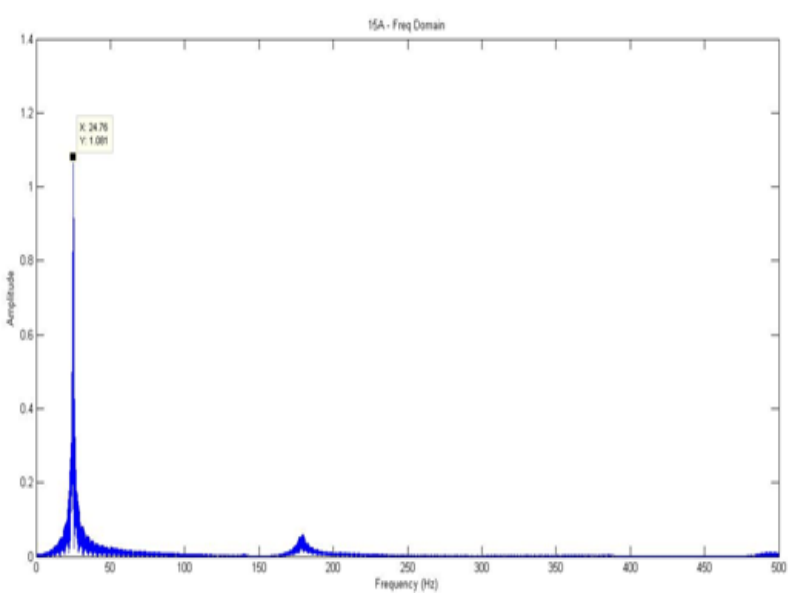

Fig. 6: (D) Sample4, Freq (Hz) vs Amp (G).

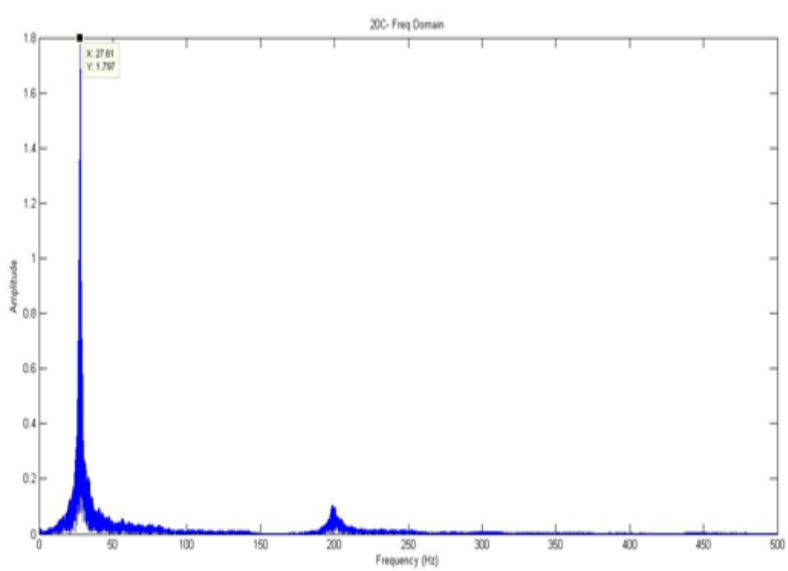

Fig. 6: (E) Sample5, Freq (Hz) vs Amp (G).

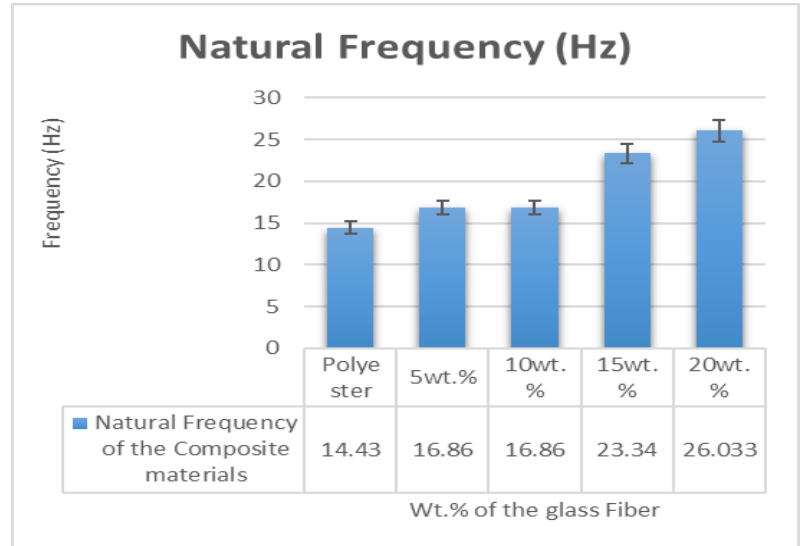

Fig. 7: Natural Frequency of Various Composites.

Fig.7. Natural Frequency values of various composite materials are shown. The value of natural Frequency of pure polyester resin is $14.43 \mathrm{~Hz}$ and polyester resin with $5 \mathrm{wt}$. percentage, $10 \mathrm{wt}$. percentage, $15 \mathrm{wt}$. percentage and $20 \mathrm{wt}$. percentage of the glass fiber values are $16.23 \mathrm{~Hz}, 16.86 \mathrm{~Hz}, 23.34 \mathrm{~Hz}$ and $26 \mathrm{~Hz}$ respectively. It is found that the maximum value of Natural Frequency of $26.033 \mathrm{~Hz}$ is obtained with the addition of $20 \mathrm{wt}$. percentage glass fiber to the composite material.

Damping Curve

Free vibration test for pure polyester and $5 \mathrm{wt} \%, 10 \mathrm{wt} \%, 15 \mathrm{wt} \%$, $20 \mathrm{wt} \%$ glass fiber-reinforced polyester composite was carried out and the obtained results are plotted as graph which gives the damping ratio of the composite sample.

Fig.8. (a) Represents the Time Vs Acceleration graph for pure polyester. Similarly Fig.8. (b), (c), (d), and (e) represents the Time Vs Acceleration graph for sample $\%, 10 \mathrm{wt} \%, 15 \mathrm{wt} \%, 20 \mathrm{wt} \%$ glass fiber-reinforced polyester composite respectively.

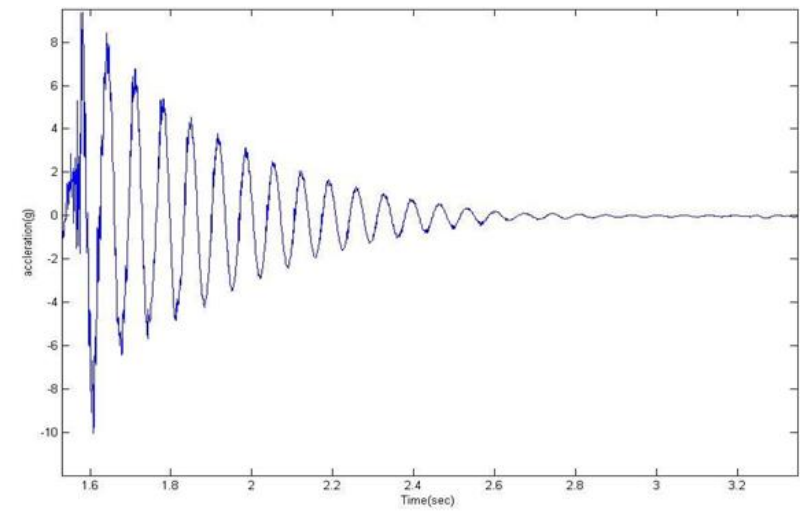

Fig. 8: (A) Time History of Polyester.

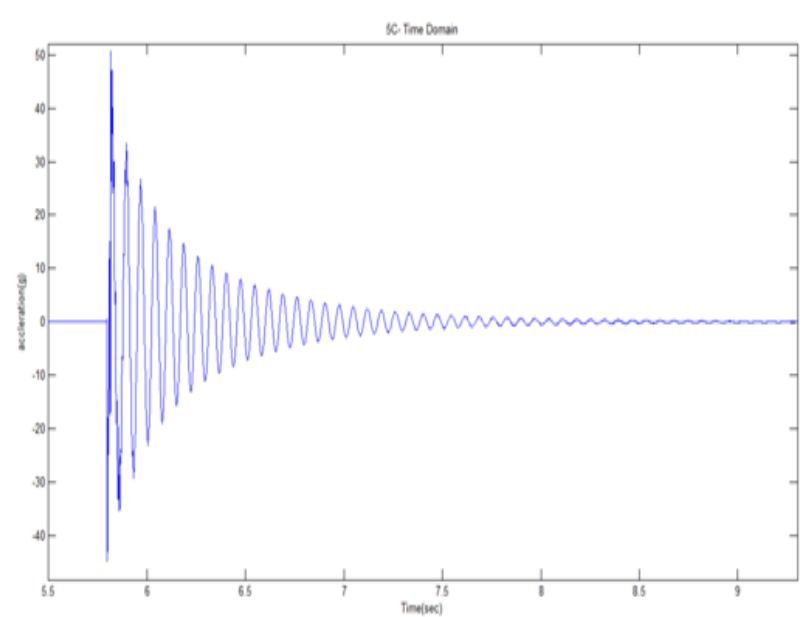

Fig. 8: (B) Time History of 5wt. Percentage of Fiber. 


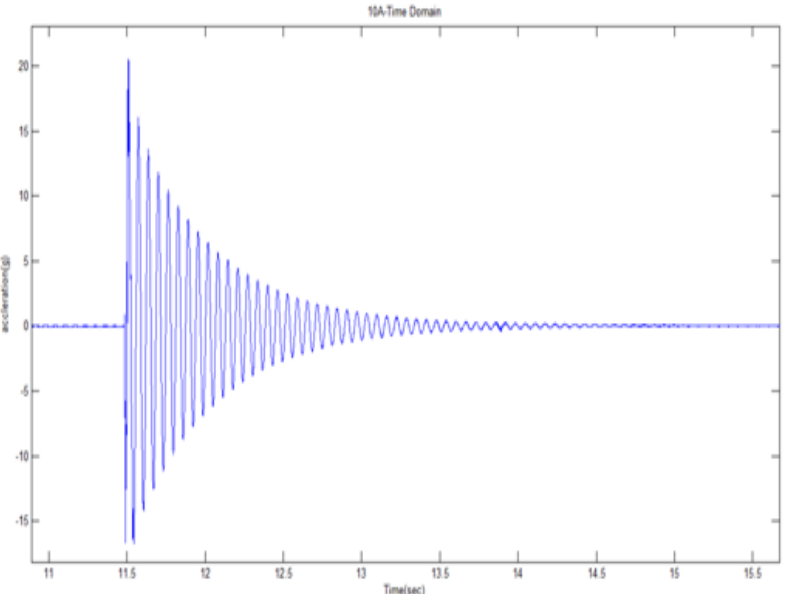

Fig. 8: (C) Time History of 10wt. Percentage of Fiber.

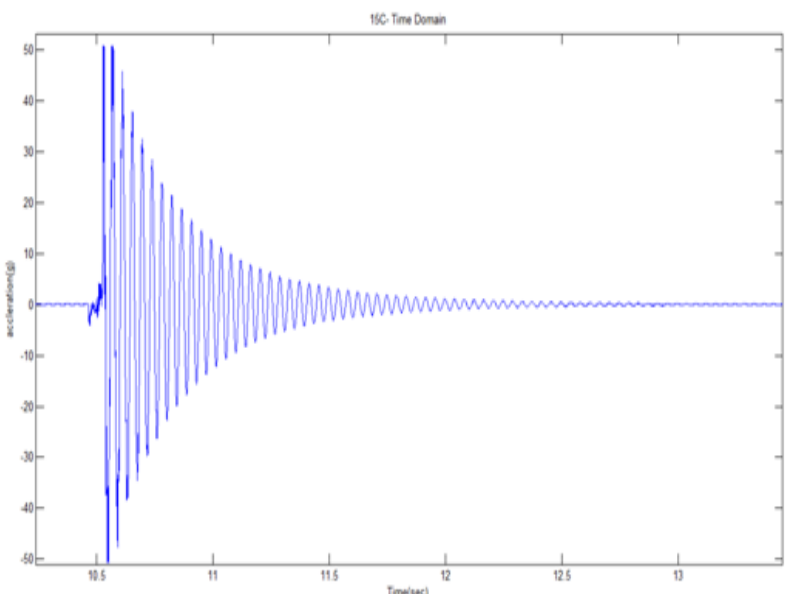

Fig. 8: (D) Time History of 15 wt. Percentage of Fiber.

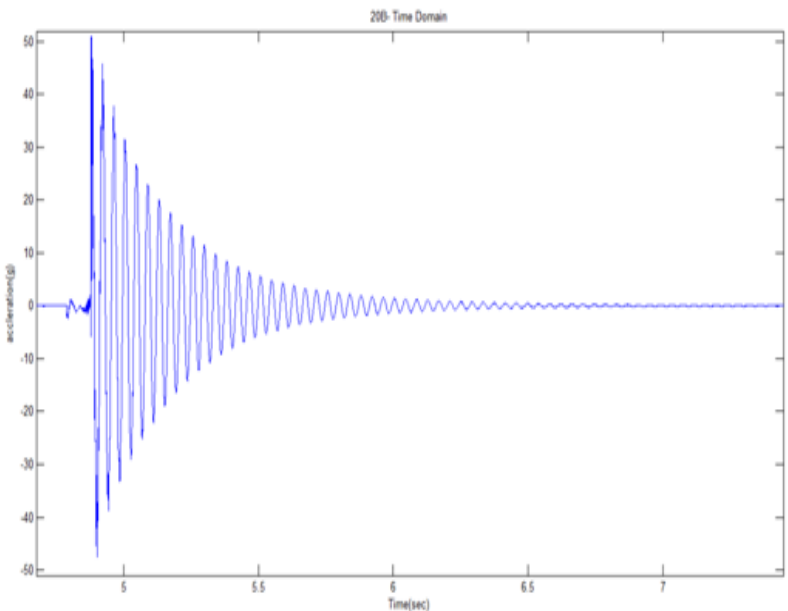

Fig. 8: (E) Time History of 20wt. Percentage of Fiber.

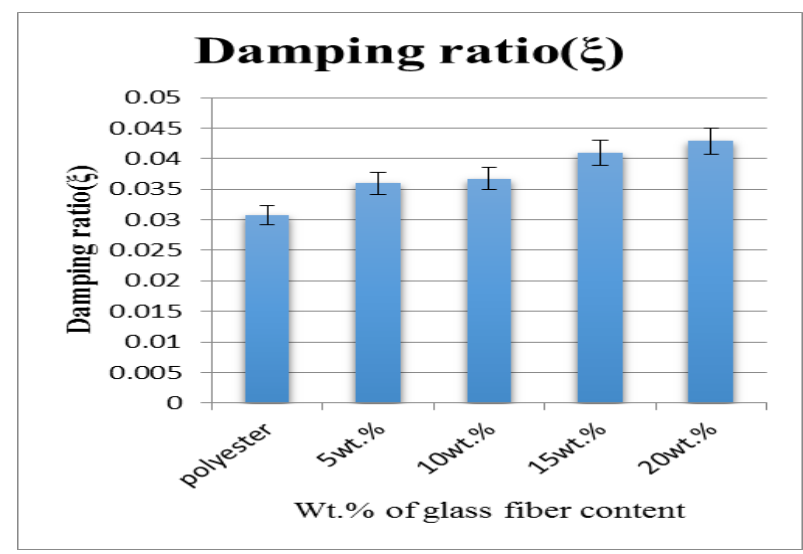

Fig. 9: Damping Ratio.
Calculation for Damping Ratio

Find out the Damping ratio of the material using logarithmic decrement Formula 2

$\ln \frac{x_{0}}{x_{1}}=\frac{2 \pi z}{\sqrt{1-z^{2}}}$

Where

$\mathrm{X}_{0}$ is $\mathrm{i}^{\text {th }}$ peak

$\mathrm{X}_{1}$ is the peak acceleration of the peak after $i^{\text {th }}$ peak.

Pure Polyester $x_{0}=4.799$

$x_{1}=3.792$

$x_{2}=3.323$

$x_{\mathrm{a}}=2.697$

These values are taken from the acceleration Vs time graph of pure polyester.

$\ln \frac{4.799}{3.792}=\frac{2 \pi \varepsilon}{\sqrt{1-\varepsilon^{2}}}$

$\varepsilon=0.0307$

Table 6: Damping Ratio of Glass Fiber Composite Materials

\begin{tabular}{|c|c|c|c|c|c|}
\hline Samples & Polyester & $\begin{array}{l}5 w t . \% \\
\text { of fiber }\end{array}$ & $\begin{array}{l}10 w t . \% \\
\text { of fiber }\end{array}$ & $\begin{array}{l}15 \mathrm{wt} . \% \\
\text { of fiber }\end{array}$ & $\begin{array}{l}20 \mathrm{wt} . \% \\
\text { of fiber }\end{array}$ \\
\hline 1 & 0.0375 & 0.017 & 0.01943 & 0.0248 & 0.0257 \\
\hline 2 & 0.0264 & 0.0162 & 0.01562 & 0.0186 & 0.0171 \\
\hline 3 & 0.0283 & 0.0201 & 0.01706 & 0.0134 & 0.0217 \\
\hline Average & 0.0307 & 0.036 & 0.0367 & 0.041 & 0.0429 \\
\hline
\end{tabular}

Fig.9.The Damping Ratio values of various composite materials are shown. The value of Damping Ratio of polyester resin is 0.0307 and polyester resin with $5 \mathrm{wt}$. \%, 10wt. \%, 15wt. \% and $20 \mathrm{wt}$. $\%$ of the glass fiber values are $0.036,0.0367,0.041$ and 0.0429 respectively. It is found that the maximum value of damping ratio of 0.0429 is obtained with the addition of $20 \mathrm{wt}$. percentage glass fiber to the composite material.

\begin{tabular}{lll}
\multicolumn{3}{c}{ Table 7: Decay Time } \\
\hline S.No & Sample & Time(sec) \\
\hline 1 & Pure polyester & 3 \\
2 & 5wt.\% of fiber & 3.9 \\
3 & 10wt.\% of fiber & 3.725 \\
4 & 15wt.\% of fiber & 2.669 \\
5 & 20wt.\% of fiber & 2.614 \\
\hline
\end{tabular}

It is observed that the decay time decreases with the addition of glass fiber, the minimum decay time is in 20wt. percentage of glass fiber composite materials.

\section{Conclusions}

In this work, free vibration testing and dynamic mechanical study inspected vibration and damping characteristics behavior of short glass fiber-reinforced polyester composites. It is concluded that the addition of glass fiber increases the natural frequency $(26.33 \mathrm{~Hz})$ and damping ratio (0.0429).It is found that the maximum value of Storage modulus (7.8GPa) and loss modulus of $(3.5 \mathrm{E}+07 \mathrm{~Pa})$ are obtained with the addition of $20 \mathrm{wt}$. percentage glass fiber to the composite material. It is found that the minimum value of damping factor 0.48 is obtained with the addition of $20 \mathrm{wt}$. percentage of glass fiber to the composite material. These results encourage using glass fiber reinforced composite in vehicles' parts where vibration absorption is of big fright. In addition, the frequency has adverse effect on the damping property of the composite. 


\section{References}

[1] AEtaati, S AbdananMehdizadeh, H Wang and S Pather. Vibration damping characteristics of short hemp fiber thermoplastic composites. Journal of Reinforced Plastics and Composites, DOI 10.1177/0731684413512228

[2] P. A. Sreekumar, P. Selvin Thomas, Jean Marc Saiter, G. Unnikrishnan and Sabu Thomas. Viscoelastic and thermal oroperties of ecofriendly composites fabricated by resin transfer molding. Journal of Reinforced Plastics and Composites 30(17), 1509-1516, 2011.

[3] J. Chandradass, M. Ramesh Kumar and R. Velmurugan. Effect of nanoclay addition on vibration properties of glass fibre reinforced vinyl ester composites. Materials Letters 61, 4385-4388, 2007.

[4] M. Jawaid, H.P.S. Abdul Khalil, Azman Hassan, Rudi Dungani and A. Hadiyane." Effect of jute fibre loading on tensile and dynamic mechanical properties of oil palm epoxy composites". Composites Part B: Engineering 45,619-624, 2013.

[5] Venkateshwaran N, ElayaPerumal A, Alavudeen A and Thiruchitrambalam M. Mechanical and water absorption behavior of banana/sisal reinforced hybrid composites.Mater Design 2011; 32: 4017-4021.

[6] Venkateshwaran $\mathrm{N}$ and ElayaPerumal A. Banana fiber reinforced polymer composite - a review. J Reinf Plast Compos 2010; 29: 23872396.

[7] Uma Devi L, Bhagawan SS and Sabu Thomas. Mechanical properties of pineapple leaf fiber-reinforced polyester composites. J Appl Polym Sci 1997; 64:1739-1748.

[8] Velmurugan R and Manikandan V. Mechanical properties of palmyra/glass fiber hybrid composite. Composite Part-A 2009; 38: 2216-2226.

[9] Libo Yan. Effect of alkali treatment on vibration characteristics and mechanical properties of natural fabric reinforced composites. DOI: $10.1177 / 0731684412449399$.

[10] N Rajini, JT Winowlin Jappes, S Rajakarunakaran and P Jeyaraj. Mechanical and free vibration properties of montmorillonite clay dispersed with naturally woven coconut sheath composite. DOI: $10.1177 / 0731684412455259$.

[11] Jean-Marie Berthelot. Damping Analysis of Orthotropic Composites with Interleaved Viscoelastic Layers: Modeling. DOI: $10.1177 / 0021998306061302$

[12] N Rajini, JT Winowlin Jappes, S Rajakarunakaran and P Jeyaraj. Mechanical and free vibration properties of montmorillonite clay dispersed with naturally woven coconut sheath composite. DOI: $10.1177 / 0731684412455259$.

[13] Daiane Romanzini, Heitor L Ornaghi, Jr., Sandro C Amico and Ademir J Zattera. Influence of fiber hybridization on the dynamic mechanical properties of glass/ramie fiber reinforced polyester composites. DOI: 10.1177/0731684412459982.

[14] Fabien Duc, Pierre-Etienne Bourban and Jan-Anders E Månson. Dynamic mechanical properties of epoxy/flax fibre composites. DOI: $10.1177 / 0731684414539779$.

[15] N. Venkateshwaran, A. ElayaPerumal and M. S. Jagatheeshwaran. Effect of fiber length and fiber content on mechanical properties of banana fiber/epoxy composite. DOI: 10.1177/0731684411426810.

[16] N Rajini, JT Winowlin Jappes, S Rajakarunakaran and P Jeyaraj. Dynamic mechanical analysis and free vibration behavior in chemical modifications of coconut sheath/nano-clay reinforced hybrid polyester composite. DOI: 10.1177/0021998312462618.

[17] Laly A. Pothan, Chandy N. George, Maya Jacob John and Sabu Thomas. Dynamic Mechanical and Dielectric Behavior of BananaGlass Hybrid Fiber Reinforced Polyester Composites. DOI: $10.1177 / 0731684409103075$. 